\title{
Die schlimmste Überraschung war die absolute Ohnmacht ...
}

\author{
Bernhard Lauterburg \\ Prof. em. Dr. med., Facharzt für Innere Medizin
}

Das im Titel erwähnte Eingeständnis des unerwarteten Unvermögens in der Behandlung der Influenza reflektiert die Enttäuschung der Ärzte über den Ausgang des Kampfs gegen die Grippe 1918/1919 [1]. Die Grippe rüttelte am Selbstverständnis der Medizin, die sich bereits auf dem Weg zur Ausrottung der Infektionskrankheiten glaubte.

Während der Grippe-Pandemie von 1918/1919 erkrankten in der Schweiz geschätzte zwei Millionen Menschen, 24500 starben, wobei $60 \%$ der Todesopfer in der Altersgruppe der 20- bis 40-Jährigen lagen [2]. Notspitäler mussten eingerichtet werden, und es fehlten Personal, Transportmittel, Medikamente und Geld, so dass das Amerikanische Rote Kreuz die Schweiz 1918 mit 125000 US Dollar zur Bekämpfung der «Spanish Grip» unterstützte [3]. Unter hospitalisierten Patienten war die Letalität trotz aller therapeutischen Bemühungen sehr hoch [4-7]. So starben im Universitätsspital Zürich 13,3\% der 2867 Patienten mit Influenza, von den 928 Patienten mit zusätzlicher Pneumonie gar 40\% [4]. In den Kliniken kämpften die Ärzte mit neuen Therapiekonzepten gegen die Grippe an, deren vier Pfeiler gemäss einer zeitgenössischen Abhandlung «Desinfektion, Immunität, Toxinbindung, Kollapstherapie» waren [8]. Was diese Therapien beinhalteten, auf welchen pathophysiologischen Konzepten sie basierten und wie sie beurteilt wurden, ist Thema der folgenden Untersuchung, die sich vorwiegend auf zeitgenössische Erfahrungsberichte aus Schweizer Spitälern stützt.

\section{Zeitgenössische Vorstellungen über die Ätiologie der Grippe}

Kochs Postulate des mikroskopischen Nachweises eines Erregers, seiner Kultivierbarkeit und der Übertragbarkeit mit typischer Erkrankungsfolge bildeten die Grundlage des Denkens über Infektionskrankheiten zur Zeit der Pandemie von 1918/1919. Der Erreger der Influenza passte aber nicht in dieses Schema. Der von Pfeiffer entdeckte «Influenza Bazillus» - später umbenannt in Haemophilus influenzae - galt nicht mehr als der primäre Erreger, wurde jedoch neben Strepto-, Staphylo- und Pneumokokken als wichtiges sekundäres infektiöses Agens betrachtet, das für die meisten fata- len Komplikationen der Influenza verantwortlich war. Nach Hermann Sahli, Ordinarius für Innere Medizin in Bern, war das eigentliche Influenzagift noch «völlig unbekannt» und deshalb wahrscheinlich in der Gruppe der unsichtbaren und filtrierbaren ultramikroskopischen Erreger zu suchen [9].

\section{Immuntherapien}

Die Erfolge in der Behandlung der Diphtherie Ende des 19. Jahrhunderts hatten dem Konzept zum Durchbruch verholfen, Infektionskrankheiten mit vom Körper selbst gebildeten Antitoxinen zu bekämpfen. Sahli propagierte die Behandlung der Influenza-Pneumonie mit Anti-Streptokokken-Serum, obwohl gemäss seiner Theorie des «komplexen Virus» ein polyvalentes Antiserum indiziert gewesen wäre [9]. Die Wahl fiel aber auf Anti-Streptokokken-Serum, da in den eitrigen Pleuraergüssen, im Auswurf und postmortem in den pneumonischen Herden von Grippekranken massenhaft Streptokokken gefunden wurden. Die klinische Wirkung war offenbar wenig überzeugend. Immerhin liess sich eine Wirkung des Serums auf das Blutbild objektivieren, was als messbarer Erfolg der Therapie gedeutet wurde: Die nach einer initialen Leukopenie auf die Seruminjektion folgende Leukozytose - so die Interpretation - stärkte die Defensivkräfte und brachte erst dadurch die desinfizierende Wirkung des Chinins, das oft zusammen mit dem Serum verabreicht wurde und "eine wirkliche Verbesserung der Heilresultate» zur Folge hatte, voll zur Geltung [1].

Da Antiseren kommerziell kaum erhältlich waren, wurden in einigen Kliniken Patienten mit Influenza und Pneumonie als Notlösung "5-20 ccm der Vene womöglich Blutsverwandten entnommenes Rekonvaleszentenblut» verabreicht, das Antitoxine gegen die relevanten Erreger enthalten sollte [5]. «Wir haben damit nie geschadet, vielleicht in einigen Fällen genützt», fasste Liebmann die Erfahrungen in Zürich zusammen, und er beurteilte die Wirkung trotz einer Mortalität der behandelten Fälle von $32 \%$ als günstig, wobei er einräumte, «dass rasche und plötzliche Wendung zum Besseren auch ohne jeglichen therapeutischen Eingriff bei dieser Erkrankung nicht selten vor- 


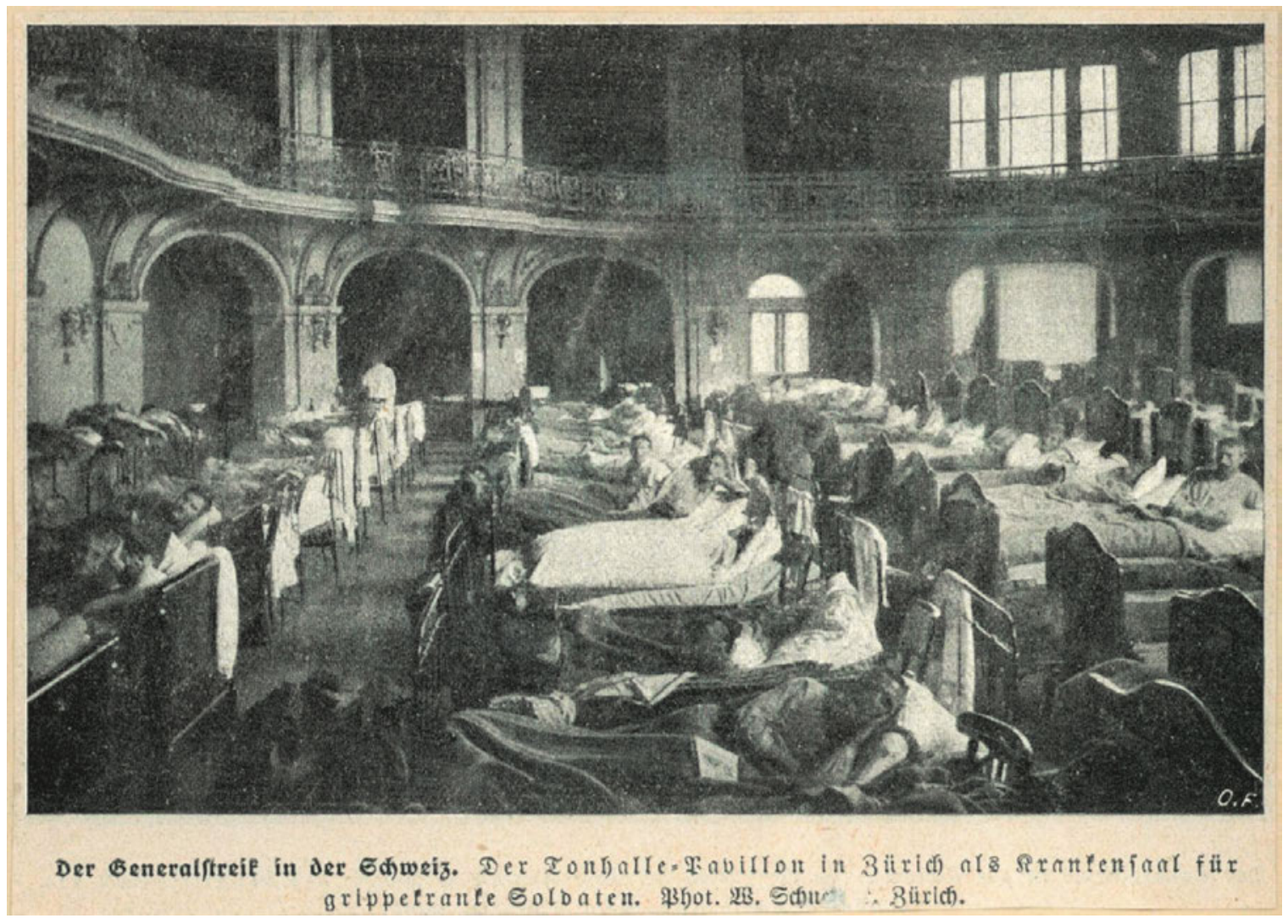

Fotoreproduktion aus einer zeitgenössischen Zeitung.

kommt» [10]. Eine Meta-Analyse von zeitgenössischen Daten kam 2006 zum Schluss, dass Rekonvaleszentenblut eine der wenigen wirksamen Massnahmen gegen die Grippe gewesen sein könnte [11].

Impfungen gegen vermutliche Grippeerreger wurden sowohl als Prophylaxe wie auch als Therapie verabreicht [12]. Sahli impfte die ganze Krankenhausabteilung mit einer Aufschwemmung von «Influenzabacillen» [13]. Dies widersprach zwar seiner Theorie des «komplexen Virus», doch begründete er die Abweichung damit, dass in einer «Mischvakzine [...] unter Umständen die Dosen der Komponenten in unzweckmässiger Weise gegen einander abgestuft sind" [13]. Die Impfung provozierte jedoch grippeähnliche Symptome, worauf das Prozedere revidiert und mit einer reduzierten Dosis jeder zweite Spitaleintritt geimpft wurde [13]. Resultate dieses frühen Beispiels einer quasi randomisierten Studie sind nicht bekannt.

\section{Die «innere Desinfektion»}

Chinin hatte sich in der Therapie der Malaria bewährt, und kurz vor dem Krieg wurden antibakterielle Eigenschaften von Chinin-Alkaloiden entdeckt. Damit, meinte der Berliner Bakteriologe Julius Morgenroth, sei «der Weg zu einer erfolgreichen inneren Desinfek- tion gewiesen" [14]. 1913 wurde das Chinin-Derivat Optochin gegen Infektionen mit Pneumokokken auf den Markt gebracht. Später folgten Eucupin und Vuzin mit den Indikationen Grippe und septische Zustände, respektive Antisepsis [15]. Mit Chinin und seinen Derivaten waren nun nicht mehr die Toxine das primäre Ziel, sondern die Erreger selbst.

Von 85 im Herbst 1918 in Bern mit Optochin und Serum behandelten Patienten mit Pneumonie starben 15,3\%. $\mathrm{Da}$ die Sterblichkeit unter derjenigen vom Sommer 1918 lag und einige der behandelten Patienten in extremis behandelt wurden, so von Salis, «kann ... der Einfluss der Behandlung als unverkennbar bezeichnet werden" [1]. In Basel waren die Kliniker von Optochin hingegen nicht überzeugt, ebenfalls nicht von Salvarsan, das nach seinen Erfolgen in der Therapie der Syphilis nun ebenfalls bei Influenza zur «innerlichen Asepsis» führen sollte [16].

\section{Toxinbindung}

Von Silberpräparaten in kolloidaler Form wie Electrargol, Collargol und Septacrol wurde keine sterilisatio magna erwartet, doch sollten sie ihre Wirksamkeit dann entfalten, «wenn es zur Bildung lokaler Entzündungsherde, zur beginnenden Pneumonie» kam [9]. 
Silber sollte einerseits proteolytische Fermente freisetzen und so die Abwehr stärken und andererseits dank seiner katalytischen Eigenschaften zur «Fällung von Toxinen, Toxoalbuminen etc.» führen [8]. Damit fügten sich Silberpräparate als weiteres Element in die Therapie der Influenza ein und ergänzten die Immuntherapie und Desinfektion.

Dass in Winterthur von 80 mit Electrargol behandelten Patienten mit Pneumonie deren 10 starben, von 29 ohne Electrargol Behandelten hingegen nur einer, erschütterte den Glauben an die auf Beobachtungen im Reagenzglas beruhende Silbertherapie nicht: «die Mortalität der ohne Silber behandelten erscheint sehr günstig gegenüber der mit Silber behandelten. Dies kommt aber nur daher, dass ich [...] bei schlechter Prognose immer zum Electrargol griff» [8]. Die auch in anderen Kliniken kaum überzeugenden Resultate spornten zum Weitermachen an, denn "[...] nous ne sont pas de ceux qui se croient désarmés devant la grippe et ses complications» [6].

\section{Die Therapie der Vasomotorenlähmung}

Klinische Beobachtungen von Grippefällen liessen von Salis vermuten, «dass das Grippegift das Zentrum der Gefässinnervation früher schädigt als den motorischen Apparat des Herzens» [1]. Somit stand die sogenannte Vasomotorenlähmung im Vordergrund, und es wurden nicht vorrangig Digitalis-Präparate, sondern Stimulantien wie Coffein, Strychnin, Adrenalin und drei- bis fünfmal täglich intramuskulär injiziertes Kampferöl verabreicht. Die behandelnden Ärzte konstatierten «stets nach der Kampfergabe eine Besserung nicht nur des Pulses und der Atmung, sondern vor allem des Allgemeinbefindens" [17]. In Basel hatten die Ärzte den «Eindruck, dass dadurch nicht nur nichts geschadet, sondern dass der Puls kräftiger wird» [16]. Zur Unterstützung der Herz- und Gefässmittel wurde die Darreichung kleiner Mengen Alkohol empfohlen, am besten «Champagner, wo solcher zur Verfügung steht» [1].

Die Therapieversuche der Influenza imponieren aus heutiger Sicht durch Polypragmasie und eine selbstdienliche Interpretation der erzielten Resultate. Zum Trugschluss, dass "post hoc ergo propter hoc», also dass Genesung einer Intervention und nicht dem natürlichen Verlauf der Krankheit zuzuschreiben war, bot sich keine günstigere Gelegenheit als die Influenza, welche in der enormen Mehrzahl der Fälle nach einigen Tagen von selbst abheilte.

Viele der therapeutischen Ansätze stossen heute auf Unverständnis, doch gilt es die ausserordentliche Situation zu berücksichtigen, in der sich die Ärzte in den Kliniken befanden. Mit der hohen Letalität von meist jüngeren Patienten konfrontiert, war therapeutischer Nihilismus für die meisten keine Option. Nur wenige rieten zur Zurückhaltung, aber auch sie griffen, wenn es den Kranken nicht bessergehen wollte, zu Koffein, Digitalispräparaten und Kampfer, die in diesen Situationen «... célèbreront des triomphes» [18].

Dass die propagierten Therapien die Erwartungen nicht erfüllten, konnten die Ärzte am Krankenbett nicht übersehen, und von Salis dürfte deren Stimmung treffend erfasst haben, als er das Unvermögen beklagte, "die schweren Pneumonien durch unsere Behandlung zu beeinflussen, was, je nach Temperament und Anlage, bei den einen die Versuchung zu therapeutischem Nihilismus, bei den andern zu einer ebenso unzweckmässigen Vielgeschäftigkeit nahelegte, bei allen aber das bedrückende Gefühl der Unsicherheit hervorrief, welches auch den Kranken nicht entgehen konnte» [1].

\section{Interessenverbindungen}

Der Autor hat keine Interessenverbindungen

\section{Literatur}

1 Salis v A. Zur Behandlung der epidemischen Grippe. Correspondenz-Blatt für Schweizer Ärzte 1919;49:953-67.

2 Sonderegger C., Die Grippeepidemie 1918/19 in der Schweiz. Unveröffentlichte Lizentiatsarbeit, Bern 1991.

3 New York Times, 9. August 1918.

4 Matter W. Über die Influenza-Epidemie 1920 nach Beobachtungen auf der Zürcher medizinischen Universitätsklinik. Zürich: 1920.

5 Frey K. Über die Influenza. Correspondenz-Blatt für Schweizer Ärzte 1919;49:1006-12.

6 Wanner F. La grippe à l'hôpital d'isolement de Vevey en juillet-aôu 1918. Correspondenz-Blatt für Schweizer Ärzte 1918;48:1729-43.

7 Bircher E. Zur Grippeepidemie. Correspondenz-Blatt für Schweizer Ärzte 1918;48:1338-40.

8 Koller H. Zur Behandlung der Grippe mit Electrargol. Correspondenz-Blatt für Schweizer Ärzte 1919;49:1633-40.

9 Sahli H. Über die Influenza. I. Wesen und Ätiologie der Influenza. Der Begriff des komplexen Virus. Correspondenz-Blatt für Schweizer Ärzte 1919;49:1-18.

10 Liebmann E. Über die Behandlung schwerer Influenzafälle mit Rekonvaleszentenserum. Correspondenz-Blatt für Schweizer Ärzte 1918;48:1393-1405

11 Luke TC, Kilbane EM, Jackson JL, Hoffman SL. Meta-analysis: convalescent blood products for Spanish influenza pneumonia: $\mathrm{a} \mathrm{fu}$ ture H5N1 treatment? Ann Intern Med 2006;145(8):599-609.

12 Tottenham RE. Vaccine Treatment of Influenza. BMJ 1919;1(3028):41.

13 Sahli, H, Über die Influenza. II. Prophylaktisches, Allgemeines, Grippeschutzmasken, Grundlagen der Influenzavakzination, Correspondenz-Blatt für Schweizer Ärzte, 1919;49:193-210.

14 Morgenroth J. Die experimentelle Chemotherapie und das Problem der inneren Desinfektion bei bakteriellen Infektionen. Die Naturwissenschaften 1913;607-15.

15 Witte W. Erklärungsnotstand: Die Grippeepidemie 1918-1920 in Deutschland unter besonderer Berücksichtigung Badens. Herbolzheim: 2006

16 Massini R. Über die Therapie der Influenza. Correspondenz-Blatt für Schweizer Ärzte 1918;48:1633-8.

17 Lauener P. Zur Behandlung der Grippe. Hohe Kampferdosen bei Influenzapneumonien. Correspondenz-Blatt für Schweizer Ärzte 1919;49:93-4.

18 Demiéville P. Le traitement de la Grippe. Correspondenz-Blatt für Schweizer Ärzte 1918;48:1270-3. 